\title{
Management of liver trauma in urban university hospitals in India: an observational multicentre cohort study
}

\author{
Yash Sinha ${ }^{1}$, Monty U. Khajanchi ${ }^{2}$, Ramlal P. Prajapati ${ }^{2}$, Satish Dharap ${ }^{3}$, Kapil Dev Soni ${ }^{4}$, Vineet Kumar ${ }^{5}$, \\ Santosh Mahindrakar ${ }^{6}$ and Nobhojit Roy, ${ }^{7,8^{*}}$ (i)
}

\begin{abstract}
Background: Low- and middle-income countries (LMICs) contribute to $90 \%$ of injuries occurring in the world. The liver is one of the commonest organs injured in abdominal trauma. This study aims to highlight the demographic and management profile of liver injury patients, presenting to four urban Indian university hospitals in India.

Methods: This is a retrospective registry-based study. Data of patients with liver injury either isolated or concomitant with other injuries was used using the ICD-10 code S36.1 for liver injury. The severity of injury was graded based on the World Society of Emergency Surgery (WSES) grading for liver injuries.

Results: A total of 368 liver injury patients were analysed. Eighty-nine percent were males, with road traffic injuries being the commonest mechanism. As per WSES liver injury grade, there were 127 (34.5\%) grade I, 96 (26.1\%) grade II, $70(19.0 \%)$ grade III and 66 (17.9\%) grade IV injuries. The overall mortality was 16.6\%. Two hundred sixty-two patients (71.2\%) were managed non-operatively (NOM), and 106 (38.8\%) were operated. 90.1\% of those managed nonoperatively survived.
\end{abstract}

Conclusion: In this multicentre cohort of liver injury patients from urban university hospitals in India, the commonest profile of patient was a young male, with a blunt injury to the abdomen due to a road traffic accident. Success rate of non-operative management of liver injury is comparable to other countries.

Keywords: Injury, Liver injury, Non-operative management, Epidemiology of liver injury, Management

\section{Introduction}

Injuries account for 4.8 million lives globally, and deaths due to road traffic injuries alone are among the top 10 causes of mortality $[1,2]$. Seven to ten percent of all injuries that occur involve the abdominal region, making it the third most common region injured following traumatic brain injury (TBI) and extremity injury [3, 4].

\footnotetext{
* Correspondence: nobhojit.roy@ki.se

${ }^{7}$ Department of Global Public Health, Karolinska Institutet, Tomtebodavägen 18 A, Widerströmska Huset, SE-171 77 Stockholm, Sweden

${ }^{8}$ WHO Collaborating Centre for Research on Surgical Care Delivery in LMICS, Department of Surgery, BARC Hospital (Govt. of India), Mumbai 400094, India Full list of author information is available at the end of the article
}

Liver and spleen injuries are the commonest damages in blunt abdominal trauma [5].

Promising outcomes of non-operative management $(\mathrm{NOM})$, in paediatric splenic injuries, have shifted the definitive treatment of these injuries from operative management $(\mathrm{OM})$ to NOM $[6,7]$. Higher grade injuries to the liver can be conserved if the patient is hemodynamically stable $[8,9]$. NOM is based on the understanding that an injury which appears severe may not necessarily exsanguinate and haemostasis does occur naturally, at least in some cases. NOM is now possible because of multidetector computerised tomography (CT) scan, intervention radiology and intensive care 
monitoring along with a paradigm shift in the concept of haemostasis [10]. This has decreased the mortality and morbidity in patients with high-grade liver trauma. OM of liver injury is only considered for those who are hemodynamically unstable or if NOM fails [8].

LMICs like India contribute to $90 \%$ of all the global injury burden, which is a critical public health issue [11]. Most published literature from India is anecdotal or single-centre studies with small database [12-16]. A multicentre hospital-based registry can help in better understanding the outcomes in the management of organ-specific injuries. In 2013, a four-university hospital registry study, called Towards Improved Trauma Care Outcomes in India (TITCO), was initiated to observe the demography, injury aetiology, management and outcomes of injured patients in urban India [17]. The aim of this study is to conduct a subgroup analysis of patients with liver injuries, managed in one such a large multicentre hospital-based registry in urban India.

\section{Methods \\ Study design}

This is a retrospective registry-based study with data extracted from a prospective cohort study called Towards Improved Trauma Care Outcomes in India (TITCO). The TITCO study is a multicentre research consortium of university hospitals formed to develop a trauma registry in India.

\section{Setting}

The study was conducted in four public university hospitals in India between October 2013 and December 2015. The hospitals included in the study are from three metropolitan cities, namely Mumbai, Delhi and Kolkata. The hospitals were King Edward Memorial Hospital (KEMH) and Lokmanya Tilak Municipal General Hospital (LTMGH) in Mumbai, Jai Prakash Narayan Apex Trauma Centre (JPNATC) in New Delhi and the Institute of Post-Graduate Medical Education and Research and Seth Sukhlal Karnani Memorial Hospital (SSKM) in Kolkata.

The urban referral trauma centres are situated in Kolkata, Mumbai ( 2 centres) and Delhi, cities with populations of more than 10 million. Except for the JPNATC, which is a standalone trauma centre, the others are trauma units providing trauma care as a part of a general hospital. The user fees are nominal and classified as free to public. The hospitals mainly serve the lower socioeconomic strata of the population in their respective area. Each of these hospitals receives 40 to 100 major trauma patients per week. They have round the clock emergency services, imaging, operating theatres and sub-speciality available.

\section{Source and method of participant selection}

All admitted patients that presented with history of trauma on arrival to any of the study hospitals were included in the TITCO registry. Data of patients with liver trauma either isolated or concomitant with other injuries was extracted using the ICD-10 code S36.1 for liver injury.

\section{Data collection}

Project officers included those with a master in science, who were then trained in the methods of data selection for the study in a workshop format, for a period of 1 week. These trained project officers at each hospital worked 8-h shifts with a rotating schedule between day, evening and night shifts through all days of the week. Data from patients admitted outside of the shift hours was collected retrospectively from the hospital medical records. The patients were followed up until discharge, death or to a maximum of 30 days. If discharged before 30 days, the patients were considered to be alive at 30 days. There was no follow-up after patient discharge or after the 30 days.

\section{Study variables}

The primary outcome was 30-day in-hospital mortality following liver injury. Patients who died during their hospital stay up to 30 days were recorded. Those discharged before 30 days were considered to be alive at 30 days. The data set was analysed for patients' demographic profile, mechanism of injury, severity, management and outcome.

The data also included serially recorded parameters like pulse, systolic blood pressure (SBP), Glasgow Coma Score (GCS) and interventions done, if any. Those patients with a systolic blood pressure of $\leq 90 \mathrm{mmHg}$ were considered as hemodynamically unstable having hypotension.

The severity of injury has been graded based on the World Society of Emergency Surgery (WSES) guidelines. WSES grading of liver injuries has been graded based on the American Association of Surgery for Trauma (AAST) scale (anatomical classification of liver injuries) and the hemodynamic stability (physiological parameter) for grading liver injuries from I-IV [8]. The classification has been added as an additional file (see Additional file 1). Management of liver injury in these four centres was not as per the WSES guidelines for liver trauma. WSES liver injury grades were first published in 2015, by which time the participating centres finished data collection.

Patients' management was divided and labelled as operative management $(\mathrm{OM})$ in those who underwent laparotomy and NOM in those who were conservatively managed without a laparotomy. Those patients who survived NOM were labelled as successfully managed. The 
patients who died after NOM were labelled as NOM failure. The overall management of these patients along with the treatment for other associated injuries was recorded.

\section{Quantitative variables}

All continuous variables were represented as mean with their standard deviation and categorical variables as counts and proportions. ISS was represented as median with inter-quartile range.

\section{Results}

\section{Demographics and liver trauma profile (Table 1)}

Out of the 16,047 trauma patients in the TITCO registry, 1134 (7.1\%) patients suffered abdominal trauma, of which 368 (32.5\%) had liver trauma. Age range varied between 2 and 80 years with the mean age of 26 years with 328 (89\%) being males. The main mechanism of injury was road traffic injury (RTI) accounting for $57 \%$ of the patients. Among the RTI, the largest group were motorcyclist injuries (30.48\%). More than half of the patients were transferred patients from other referral centres (58.2\%). $91.5 \%$ of the cohort with liver injuries had blunt injuries. Eighty-eight (24.5\%) patients presented on arrival with SBP of $\leq 90 \mathrm{mmHg}$.

Most of liver trauma patients belonged to WSES grades I-III (75\%). Nine patients could not be classified as WSES grade as their systolic blood pressure was missing. The most common intra-abdominal injuries associated with liver trauma were spleen (17\%) and kidney (14\%) (Fig. 1). Eighty-five patients had an associated TBI of which $38(44.7 \%)$ had moderate to severe TBI based on GCS.

\section{Management and outcome in liver injury (Fig. 2) \\ Diagnostic modalities}

Focused Assessment with Sonography in Trauma (FAST) was done in 345 patients (93.8\%), and a CT scan was done in $310(84.24 \%)$ patients included in the study.

\section{Overall mortality}

Overall, 30-day in-hospital mortality rate in this cohort of liver injury with/without other injuries was $16.6 \%$ (61 out of 368).

Table 1 Demographics and clinical profile of patients with liver injury

\begin{tabular}{|c|c|c|}
\hline Variables & Value $(n=368)$ & Missing values $(n)$ \\
\hline Age & $26(12.7)$ & 0 \\
\hline Male, $n(\%)$ & $328(89 \%)$ & 0 \\
\hline Mechanism of injury & & 2 \\
\hline 1. Road traffic accident & $210(57.07 \%)$ & \\
\hline 2. Railways & $24(6.52 \%)$ & \\
\hline 3. Assault & $39(10.6 \%)$ & \\
\hline 4. Falls & $79(21.47 \%)$ & \\
\hline 5. Other & $14(3.8 \%)$ & \\
\hline Blunt injury & $337(91.6 \%)$ & 0 \\
\hline Heart rate (beats per minute) & 99 (19.3) & 8 \\
\hline Systolic BP (mmHg) & $108(23.4)$ & 9 \\
\hline Haemoglobin, g/dl (mean \pm SD) & $11(2.1)$ & 21 \\
\hline ISS score, median (IQR) & $17(10-22)$ & \\
\hline GCS score & $13.4(3.3)$ & 11 \\
\hline Length of stay, in days, median (IQR) & $8.5(4.8-15.0)$ & 2 \\
\hline Units of blood received in those operated (mean) & 1.8 units $(2.0)$ & - \\
\hline WSES liver injury grade & & 9 \\
\hline I & $127(34.5 \%)$ & \\
\hline ॥ & $96(26.1 \%)$ & \\
\hline III & 70 (19.0\%) & \\
\hline IV & $66(17.9 \%)$ & \\
\hline NA (as SBP missing) & $9(2.4 \%)$ & \\
\hline
\end{tabular}

Continuous variables are represented by mean with their standard deviation in parentheses except for ISS and length of stay where they are shown as median and IQR. Categorical variables are represented as counts and proportions in parenthesis 


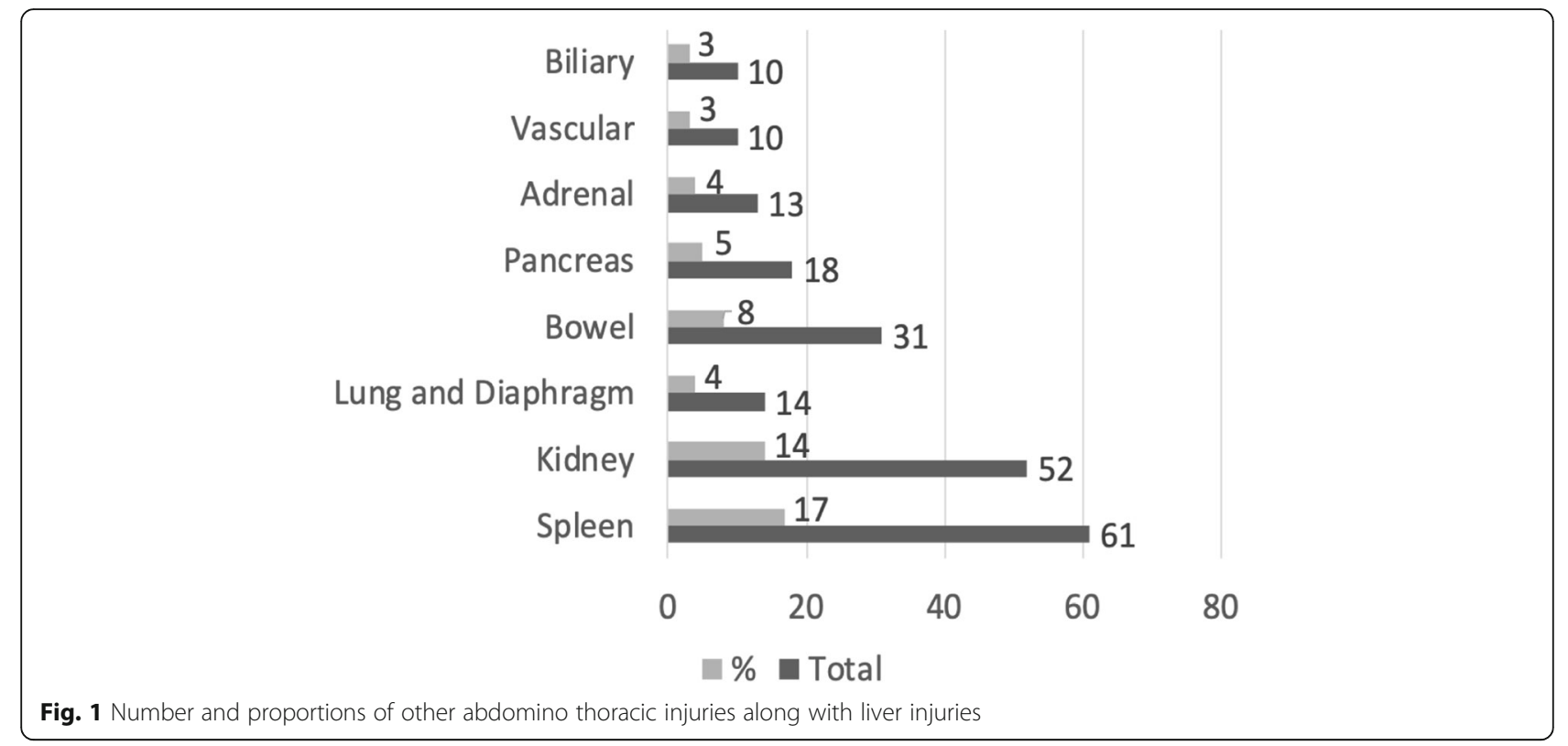

\section{Non-operative management}

Out of 368 patients with liver trauma and other associated injuries, $262(71.2 \%)$ patients had NOM. The NOM as per various WSES grade of liver injury is shown in Table 2. Among these, 236 patients (90.1\%) were successfully managed (survived) (Fig. 2). As per the WSES grades of injury, the NOM success rates were grade I-
$90.2 \%$, grade II-90.6\%, grade III-93.1\% and grade IV$81.6 \%$.

Death occurred in 26 patients (9.9\%). Four of them died within $24 \mathrm{~h}$ of arrival, 11 died between $24 \mathrm{~h}$ and 7 days after arrival and 11 died after 7 days from arrival (time data of one patient was missing). Of those who died, 7 patients had severe TBI $(<8$ GCS and

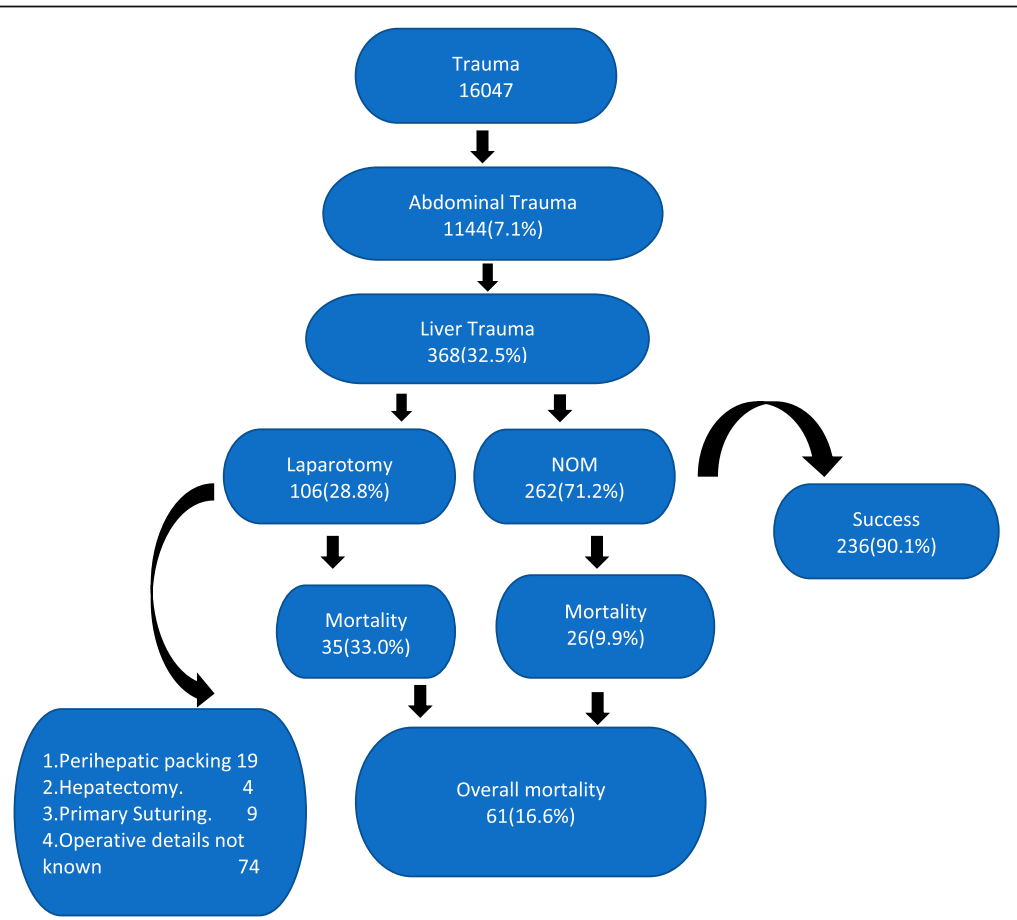

Fig. 2 Management and outcomes in liver injury patients 
Table 2 Operative and non-operative management of liver injuries as per WSES grade of liver injury

\begin{tabular}{llllll}
\hline $\begin{array}{l}\text { WSES grade of } \\
\text { liver injury }\end{array}$ & NOM (\%) & $\begin{array}{l}\text { OM for liver } \pm \text { other intra- } \\
\text { abdominal organ (a) }\end{array}$ & $\begin{array}{l}\text { OM for intra-abdominal } \\
\text { organ other than liver (b) }\end{array}$ & OM for unspecified reason (c) & $\begin{array}{l}\text { Total no. of operated } \\
(\mathbf{a}+\mathbf{b}+\mathbf{c})(\%)\end{array}$ \\
\hline I & $102(39.0)$ & 7 & 13 & 5 & $25(23.6)$ \\
II & $64(24.4)$ & 11 & 16 & 5 & $32(30.2)$ \\
III & $58(22.1)$ & 6 & 4 & 2 & $12(11.3)$ \\
IV & $33(12.6)$ & 18 & 11 & 4 & $33(31.1)$ \\
NA & $5(1.9)$ & 1 & 1 & 2 & $4(3.8)$ \\
Total & 262 & 43 & 45 & 18 & 106
\end{tabular}

WSES World Society Emergency Surgery, NOM non-operative management, OM operative management

intracranial injuries), 5 patients had mild TBI (> 12 GCS), 2 patients had hypotension and TBI, 5 patients had hypotension without TBI and seven had no hypotension on arrival and no TBI.

\section{Operative management}

One hundred six patients underwent emergency laparotomy which included various procedures such as packing both perihepatic and intraparenchymal haemostatic packs, direct suture ligation of lacerations, anatomic or nonanatomic segmental hepatectomy for liver injury, splenectomy, nephrectomy and bowel suturing for associated injuries. Of the 106 laparotomies, 43 (40.5\%) were for liver and/or other intra-abdominal organs, 45 $(42.5 \%)$ were for other intra-abdominal organs only (non-liver reasons) and 18(17.0\%) were for cause unspecified (Table 2). Twenty-two (20.8\%) patients with penetrating injury underwent OM. Of these 22 penetrating injuries, 3 patients died. Among the operated 106 patients, 13 patients (12\%) were taken to the operating room within $1 \mathrm{~h}$ of admission while the rest underwent surgery within $24 \mathrm{~h}$ of admission. Forty-six (43.4\%) patients did not get a CT scan done before surgery.

As per the WSES grades of injury, of those who underwent OM, 25 (23.6\%) had grade I, 32 (30.9\%) were grade II, $12(11.3 \%)$ were grade III and $33(37.7 \%)$ were grade IV liver injuries. Of the 69 grade I-III liver injury patients, 24 were operated for liver and/or other associated intra-abdominal organ injury, of which 8 had penetrating injury. The rest 45 were operated for other intraabdominal organ injury (non-liver) or for unspecified reasons (Table 2).

The operative management cohort differed from the non-operative cohort significantly in their mean SBP, 99 (26.2\%) vs. 111 (21.0\%); proportion of penetrating injury, $21.7 \%$ vs. 4.4\%; heart rate, 103 (2.4) vs. 97 (18.5); and ISS, 14 (9-22) vs. 17 (12-22). Univariate analysis showed no difference between these two cohorts in their age and GCS (Table 3). The injury severity score (ISS) in the NOM group was higher, compared to those who underwent laparotomy. One third of the patients who underwent laparotomy died (35 out of 106). The causes of death in these patients cannot purely be assigned to liver trauma as they had multiple injuries. Fourteen of them died within $24 \mathrm{~h}$ of arrival, 16 died between $24 \mathrm{~h}$ and 7 days after arrival and 8 died after 7 days (time data of one patient was missing).

\section{Discussion}

To our knowledge, this is the first analysis of an Indian multicentre cohort of liver injury patients and has one of the largest cohorts analysed in India and probably across LMICs.

In our study, a third of all the abdominal trauma patients had liver injury. More than half were RTI, and the majority were blunt type of injury to the abdomen. In our study, the proportion of liver injuries within the abdominal region was $33 \%$ and is similar to other studies

Table 3 Comparison of physiological variables of patients who underwent laparotomy vs. those who underwent non-operative management

\begin{tabular}{llll}
\hline Variables & OM $(\boldsymbol{n}=\mathbf{1 0 6})$ & NOM $(\boldsymbol{n}=\mathbf{2 6 3})$ & $\boldsymbol{p}$ value \\
\hline Age & $28(12.8)$ & $25(12.6)$ & $p=0.07 t$ test \\
Penetrating injury (\%) & $22(20.8)$ & $9(3.5)$ & $p<0.05 t$ test \\
SBP (mmHg), mean (SD) & $99(26.6)$ & $111(21.0)$ & $p<0.05 t$ test \\
Heart rate (beats per minute), mean (SD) & $103(20.4)$ & $97(18.5)$ & $p<0.05 t$ test \\
GCS, mean (SD) & $13(3.9)$ & $14(3.1)$ & $p=0.14 t$ test \\
ISS, median (IQR) & $14(9-22)$ & $17(12-22)$ & $p<0.05$ (Wilcoxon's rank-sum test) \\
Mortality, (\%) & $35(33.0 \%)$ & $26(9.9 \%)$ & $p<0.05$ chi-square \\
\hline
\end{tabular}

SBP systolic blood pressure, GCS Glasgow Coma Scale, OM operative management (laparotomy), NOM non-operative management, ISS injury severity score 
from India which reported $23-35 \%$ of all the abdominal injuries [18-20]. However, this is lower than the proportion of $42-52 \%$ reported from studies from Africa and Italy [4, 21]. In India, blunt abdominal trauma due to RTI is the commonest mechanism of injury except in the state of Jammu and Kashmir (a conflict zone) which has a higher proportion of penetrating abdominal trauma [19]. In countries where assault is common, penetrating injuries are the most common cause of abdominal injury thence liver injuries [22-24].

The mean age was 26 years with a predominance of males (89\%). This could be as liver injury occurs most commonly in young adults who extensively travel for work and engage in sporting activities compared to women [25]. Our cohort also reflects this, with RTIs being more common in males, compared to females who predominantly have falls. Consequently, liver injuries are common in males.

In our cohort of liver injury patients, $90-93 \%$ of the WSES grade I-III liver injuries were successfully managed using non-operative management (NOM) strategy. In WSES grade IV liver injuries, this number of NOM success was reduced to $84 \%$. Progress in the management of liver trauma towards the end of the twentieth century has reduced the mortality [7]. Serial imaging, advancements in critical care and adjunctive therapies like angiography, percutaneous drainage and endoscopy/ endoscopic retrograde cholangiopancreatography management of hepatic injuries have resulted in improved outcomes [9]. Literature suggests most liver injuries of grades I-III are treated by NOM with $82-100 \%$ success $[9,26,27]$. However, studies comparing OM vs. NOM in high-grade liver injury are still evolving [28]. Our comparisons of the two cohorts showed poor outcomes in those undergoing OM. On admission, the OM cohort had poor physiological variables compared to NOM, suggesting this cohort to have more serious injuries. Median ISS of OM cohort (ISS = 14) was significantly less compared to that of NOM cohort (ISS =17). ISS is a poor predictor of severity in LMICs. This has been repeatedly demonstrated in predictor studies on mortality in trauma $[29,30]$.

In our study, approximately $50 \%$ of WSES grade IV liver trauma were managed non-operatively. This is unlike the guidelines and other literature where such kind of injuries would have been operated [9, 31]. In our study, we have classified them as WSES grade IV based on the on-arrival systolic blood pressure $<90 \mathrm{mmHg}$ and any grade of injury. Systolic blood pressure is a dynamic process and changes as the patient is being resuscitated. In our opinion, the reasons for non-operative management of these grade IV liver injuries may have been due to (i) improvement of systolic blood pressure after resuscitation (responders or borderline unstable patients), (ii) unavailability of blood and blood products and (iii) lack of protocol directed treatment. Apart from these, 4 of these grade IV liver injury patients had associated severe TBI, which may be a relative contraindication to operate in some centres as the outcomes are poor in patients with severe TBI with hypovolemic shock. Eight of the WSES grade IV injury patients were operated within an hour and the rest within the first 24 $h$. These delays in LMICs like ours are due to the overwhelming number of emergencies, shortage of human resources and lack of protocol adherence [32,33].

\section{Limitations}

Data regarding the patients requiring adjunctive procedure for management of liver injury were not recorded in this study. We do not have data regarding the cause of mortality in patients who were initially managed nonoperatively. Morbidity of NOM was not recorded. The results of this study are generalisable to the urban university hospitals in India and perhaps the other similar university hospitals in LMICs.

\section{Conclusion}

In this multicentre cohort of trauma patients from urban university hospitals in India, one third of those with a blunt trauma to the abdomen suffered a liver injury. Operative management was undertaken in less than one third of those with liver injury. Success rate of nonoperative management of liver injury is comparable to other countries.

\section{Supplementary information}

The online version contains supplementary material available at https://doi. org/10.1186/s13017-020-00338-9.

Additional file 1. WSES liver trauma classification [8]. (DOCX 14 kb)

\begin{abstract}
Abbreviations
LMIC: Low- and middle-income country; WSES: World Society Emergency Surgery; OM: Non-operative management; OM: Operative management; TITCO: Towards Improved Trauma Care Outcomes; AAST: American Association of Surgery for Trauma; RTA: Road traffic accidents; TBI: Traumatic brain injury; SBP: Systolic blood pressure; ISS: Injury severity score; GCS: Glasgow Coma Scale; FAST: Focused Assessment with Sonography in Trauma
\end{abstract}

\section{Acknowledgements}

We thank the Thursday Truth Seekers and the TITCO research team for their support. Special thanks to Siddharth David who proofread this manuscript for English grammar.

\section{Authors' contributions}

Authors YS, MUK and RPP have conceptualised, designed, analysed and interpreted the data. NR and KS have contributed to the design and analysis of the manuscript. SM and SD contributed to the analysis and interpretation of data. MGW contributed to the design, concept and interpretation of data. All authors contributed to drafting the article and revising it, and approved the final version. All authors agree to be responsible for all aspects of the work. 


\section{Funding}

The data collection was funded by the Swedish National Board of Health and Welfare and the Laerdal Foundation. There is no funding to report on this submission. Open Access funding provided by Karolinska Institute.

\section{Availability of data and materials}

The data are available to whoever wants them by emailing the corresponding author or the last author (MGW). They can write their aim or objective, and then, the authors can decide if that study can be done without duplication of the work.

\section{Ethics approval and consent to participate}

The TITCO project was granted waivers of informed consent from all study centres. The study received approval from the institutional ethics committee of the four centres involved in the study. The ethics approval registration numbers were EC/NP-279/2013 RP-01/2013 from the All India Institute of Medical Sciences Ethics Committee, IEC/11/13 from the Lokmanya Tilak Municipal Medical College and Lokmanya Tilak Municipal General Hospital Institutional Ethics Committee, IEC/279 from the Institute of Post Graduate Medical Education and Research (IPGME\&R) Research Oversight Committee (Institutional Ethics Committee) and IEC(I)OUT/222/14 from the Seth GS Medical College and King Edward Memorial Hospital Institutional Ethics Committee.

\section{Consent for publication}

Not applicable

\section{Competing interests}

None declared

\section{Author details}

${ }^{1}$ Gastrointestinal Surgery, Sanjay Gandhi Post Graduate Institute, Rai Bareily Road, Lucknow, Uttar Pradesh 226014, India. ${ }^{2}$ Seth GSMC and KEM Hospital, Dr E Borges Road, Mumbai 400012, India. ${ }^{3}$ Topiwala National Medical College \& B.Y.L. Nair Charitable Hospital, Mumbai 400008, India. ${ }^{4}$ JPN Apex Trauma Center, All India Institute of Medical Sciences, Raj Nagar, Safdarjung Enclave, New Delhi 110029, India. ${ }^{5}$ LTMMC \& LTMG Hospital, Sion, Mumbai, India. ${ }^{6}$ Innovative Alliance for Public Health, New Delhi, H. No 87F, H Block, Phase 6, Taj Avenue, Ayanagar, New Delhi 110047, India. ${ }^{7}$ Department of Global Public Health, Karolinska Institutet, Tomtebodavägen 18 A, Widerströmska Huset, SE-171 77 Stockholm, Sweden. ${ }^{8}$ WHO Collaborating Centre for Research on Surgical Care Delivery in LMICs, Department of Surgery, BARC Hospital (Govt. of India), Mumbai 400094, India.

Received: 18 July 2020 Accepted: 28 September 2020

Published online: 15 October 2020

\section{References}

1. Haagsma JA, Graetz N, Bolliger I, et al. The global burden of injury: incidence, mortality, disability-adjusted life years and time trends from the global burden of disease study 2013. Inj Prev. 2016;22:3-18.

2. (2017) WHO | Top 10 causes of death. WHO

3. Ferrah N, Cameron P, Gabbe B, Fitzgerald M, Martin K, Beck B. Trends in the nature and management of serious abdominal trauma. World J Surg. 2019; 43:1216-25.

4. Costa G, Tierno SM, Tomassini F, Venturini L, Frezza B, Cancrini G, Stella F. The epidemiology and clinical evaluation of abdominal trauma. An analysis of a multidisciplinary trauma registry. Ann Ital Chir. 2010;81:95-102.

5. Badger SA, Barclay R, Campbell P, Mole DJ, Diamond T. Management of liver trauma. World J Surg. 2009;33:2522-37.

6. Lucas CE. Splenic trauma. Choice of management. Ann Surg. 1991;213:98-112.

7. Richardson JD, Franklin GA, Lukan JK, Carrillo EH, Spain DA, Miller FB, Wilson MA, Polk HC, Flint LM. Evolution in the management of hepatic trauma: a 25-year perspective. Ann Surg. 2000;232:324-30.

8. Coccolini F, Coimbra R, Ordonez C, et al. Liver trauma: WSES 2020 guidelines. World J Emerg Surg. 2020;15:24.

9. Coccolini F, Montori G, Catena F, et al. Liver trauma: WSES position paper. World J Emerg Surg. 2015;10:39.

10. Malhotra AK, Fabian TC, Croce MA, Gavin TJ, Kudsk KA, Minard G, Pritchard FE. Blunt hepatic injury: a paradigm shift from operative to nonoperative management in the 1990s. Ann Surg. 2000;231:804-13.
11. Hofman K, Primack A, Keusch G, Hrynkow S. Addressing the growing burden of trauma and injury in low- and middle-income countries. Am J Public Health. 2005;95:13-7.

12. Malhotra P, Sharma D, Gupta S, Minhas SS (2017) Clinico epidemiological study of blunt abdominal trauma in a tertiary care hospital in north western Himalayas file://Users/yashsinha/Downloads/10596-42227-1-PB.pdf. Int Surg J 4:874-882.

13. Karim T, Topno M, Reza A, Patil K, Gautam R, Talreja M, Tiwari A. Hepatic trauma management and outcome; our experience. Indian J Surg. 2010;72: 189-93.

14. Ragavan M, Duraiprabhu A, Madan R, Murali K, Francis G, Subramanian M. Posttraumatic intrahepatic bilioma. Indian J Surg. 2015;77:1399-400.

15. Gupta S, Talwar S, Sharma RK, Gupta P, Goyal A, Prasad P. Blunt trauma abdomen: a study of 63 cases. Indian J Med Sci. 1996;50:272-6.

16. Parray FQ, Wani ML, Malik AA, et al. Evaluating a conservative approach to managing liver injuries in Kashmir, India. J Emergencies, Trauma Shock. 2011;4:483-7.

17. Roy N, Gerdin M, Ghosh S, Gupta A, Kumar V, Khajanchi M, Schneider EB, Gruen R, Tomson G, von Schreeb J. 30-day in-hospital trauma mortality in four urban university hospitals using an Indian trauma registry. World J Surg. 2016. https://doi.org/10.1007/s00268-016-3452-y.

18. Umare GM, Sherkar N, Motewar A (2018) Study of clinical profile and management of blunt abdominal trauma.

19. Lone GN, Peer GQ, Wani KA, Bhat AM, Wani NA, Bhat A. An experience with abdominal trauma in adults in Kashmir. JK Pract. 2001;8:225-30.

20. Mehta N, Babu S, Venugopal K. An experience with blunt abdominal trauma: evaluation, management and outcome. Clin Pract. 2014. https://doi.org/10.4081/cp.2014.599.

21. Ntundu SH, Herman AM, Kishe A, Babu H, Jahanpour OF, Msuya D, Chugulu SG, Chilonga K Patterns and outcomes of patients with abdominal trauma on operative management from northern Tanzania: a prospective single centre observational study. doi: https://doi.org/10.1186/s12893-019-0530-8

22. Kalil M, Amaral IMA. Epidemiological evaluation of hepatic trauma victims undergoing surgery. Rev Col Bras Cir. 2016;43:22-7.

23. Bilgiç I, Gelecek S, Akgün AE, Özmen MM. Evaluation of liver injury in a tertiary hospital: a retrospective study. Ulus Travma ve Acil Cerrahi Derg. 2014:20:359-65.

24. Zago TM, Pereira BM, Nascimento B, Alves MSC, Calderan TRA, Fraga GP. Hepatic trauma: a 21-year experience. Rev Col Bras Cir. 2013;40:318-22.

25. Schweizer W, Studer E, Huber A, Blumgart LH. Epidemiology of liver injuries in 14 district, urban, regional and canton hospitals in Switzerland. Helv Chir Acta. 1991;57:941-9.

26. Stassen NA, Bhullar I, Cheng JD, et al. Nonoperative management of blunt hepatic injury. J Trauma Acute Care Surg. 2012;73:S288-93.

27. Jyothiprakasan VK, Madhusudhan C, Reddy CS. Study of blunt trauma abdomen involving liver injuries based on grade of injury, management: a single centre study. Int Surg J. 2019;6:793.

28. Cirocchi $R$, Trastulli S, Pressi E, Farinella E, Avenia S, Morales Uribe $\mathrm{CH}$ ernando, Botero AM Aria, Barrera LM (2015) Non-operative management versus operative management in high-grade blunt hepatic injury. Cochrane database Syst Rev 8:CD010989.

29. Roy N, Gerdin M, Schneider E, et al. Validation of international trauma scoring systems in urban trauma centres in India. Injury. 2016;47:2459-64.

30. Laytin AD, Kumar V, Juillard CJ, Sarang B, Lashoher A, Roy N, Dicker RA. Choice of injury scoring system in low- and middle-income countries: lessons from Mumbai. Injury. 2015. https://doi.org/10.1016/j.injury.2015.06.029.

31. Afifi I, Abayazeed S, El-Menyar A, Abdelrahman H, Peralta R, Al-Thani H. Blunt liver trauma: a descriptive analysis from a level I trauma center. BMC Surg. 2018;18:42

32. Maine RG, Kajombo C, Purcell L, Gallaher JR, Reid TD, Charles AG. Effect of in-hospital delays on surgical mortality for emergency general surgery conditions at a tertiary hospital in Malawi. BJS Open. 2019;3:367-75.

33. Gupta S, Khajanchi M, Kumar V, Raykar NP, Alkire BC, Roy N, Park KB. Third delay in traumatic brain injury: time to management as a predictor of mortality. J Neurosurg. 2020;132:289-95.

\section{Publisher's Note}

Springer Nature remains neutral with regard to jurisdictional claims in published maps and institutional affiliations. 